\title{
THREE FORMS OF THE HUMAN NOSE
}

\author{
ROBERT BENNETT BEAN \\ From the Medical Department, Tulane University
}

The three most distinct forms of the human nose appear characteristically in different parts of the earth and the forms are clearly geographical, evolutional, and developmental. The first of the three is the under-developed nose resembling that of the infant, and this form has been called by me the 'hypo-phylo-morph;' the second is a massive nose, the 'meso-phylo-morph;' and the third is the thin, high, long, narrow nose, the 'hyper-phylomorph.'

The hypo-phylo-morph nose is flat, broad, and short, with flat depressed bridge, upturned tip, and the nostrils open forward rather than downward. The nostrils flare and are wide open, and the extremity of the nose is uplifted or tilted back so that an instrument may be inserted horizontally along the floor of the nasal fossa without interference by the alae. The nasal ridge, or the bridge of the nose, is flat, because the nasal bones do not form a steep roof over the nasal passages by their apposition along the median line. The articulation of the nasal bones with the frontal bone is a gentle curve and not an abrupt transition. The supraorbital ridges and glabella are not prominent, nor the frontal sinuses large in association with this form of nose, but the cheeks are full, and the eyes prominent, therefore the front of the entire face is somewhat flat, although the lips project from a small mouth. The hypo-phylo-morph nose is essentially the nose of the infant.

The hypo-phylo-morph nose is found especially among the Malays and Negritos, as they exist today in the Malay peninsula, Java, Sumatra, Borneo, Celebes, and the Philippine archipelago, as well as among the Pigmies, Bushmen and Hottentots of Africa. It is also found in a modified form in Burma, Siam, 
Cambodia, Tonkin, Annam, in India, China, Japan, Mongolia, and among the true negroes of Africa and America. The form dwindles away through Siberia, Lapland, Finland and Russia into Europe, where the hyper-phylo-morph nose appears. The form also dwindles away through the Eskimos and Indians of the Americas, among the Polynesians and the other inhabitants of the Pacific Islands, and among the pseudo-negroes of north and east Africa, in all of which peoples the meso-phylo-morph nose appears. The hypo-phylo-morph nose is most emphatic among the women of all the countries where it appears, but is also to be seen among the men.

The meso-phylo-morph nose is massive, long and broad, not very high, with apparently depressed root due to overhanging brows and glabella: it has a straight bridge, and nostrils that open downward and slightly forward. The outlines of the nose are usually straight. Looked at from in front, the lines of contact of the nose with the face on each side are straight, and slant away widely from the inner angles of the eyes to the alae of the nose. Looked at from the side the bridge of the nose is straight or very slightly aquiline from root to tip, and the lower border (base) of the nose is straight from a point just over the akanthion to the tip of the nose, although the tip may sometimes dip below this straight line. This line is not long in relation to the breadth of the nose, but it is absolutely as long as the same line in the hyper-phylo-morph nose, and may be even longer when the nose is unusually large. The nose looks flat, due to its great breadth, when it is actually a high nose. The alae flare little although the apertures of the nostrils are large, due to the great width of the nose. The nasal bones form a more acute angle at their apposition than in the hypo-phylo-morph nose, and they pass abruptly above into the frontal bone, where the overhanging brows and the glabella give the root of the nose a depressed appearance. The malar and zygomatic bones are large and project, and the jaws are prominent both in front and at the sides of the face. The orbits are large, the bony sinuses about the nose are of great size and the lips are thick. The result is that the whole face is large, and the nose conforms with its surroundings. 
The distribution of the primary forms of the meso-phylomorph nose center among the inhabitants of the Deccan and Ceylon, among the Polynesians and the inland tribes of the Philippine Islands, Java, Sumatra, Borneo, and Celebes, and it assumes its most exaggerated form among the Tasmanians, Australians, Melanesians, pure Negritos, and true negroes. The form exists somewhat modified among the peoples who have the hypo-phylomorph nose, and is especially emphatic among the men, although it appears among the women. It fades away through northern Asia, in central Europe, through southern Asia towards the Mediterranean basin, and in eastern and northern Africa, at all of which points it merges into the nose of the hyper-phylo-morph.

The hyper-phylo-morph nose is long, high and narrow, with high root, bridge and tip, the nostrils flare but little and open almost directly downward. The nostrils may even open somewhat backward in the exaggerated forms, as in the Jew, for instance. The nose appears prominent and may seem larger than it really is, inasmuch as the jaws are not prognathous, and the brows and glabella do not overhang the nose; the forehead and chin may even recede leaving the nose projecting from the middle of the face. The nose may be retroussé, straight, sinuous, or aquiline. The retroussé, seen chiefly among women, is the underdeveloped, whereas the aquiline, seen chiefly among. men, is the exaggerated form of the hyper-phylo-morph nose. Associated with this form of nose is the long, narrow face, and the long, high, narrow head. The distance from the external auditory meatus to the tip of the nose is greater in this form than in either of the others, and this projection of the nose to a pointed tip in association with the high, narrow forehead and pointed chin give the characteristic appearance called by the Australians in derision, "the hatchet-faced Englishman."

The most representative types of the hyper-phylo-morph nose in its primary form are found in northern Europe, Great Britain, and America, among the tall blonde Nordics, and this form of nose has been modified around the Mediterranean where it is extremely fine and thin. Its most exaggerated forms are to be seen among the Jews, Arabs, and Gypsies. It is found more or 
less modified in Asia and Africa along the course of four streams of infiltration. The most intense forms (the most perfect) are in southern Asia and northern Africa, the least intense in northern Asia and eastern Africa. The Américan Indians present a hyperphylo-morph nose of an intermediate form between that of the extreme meso-phylo-morph and the primary hyper-phylo-morph. The characteristic hyper-phylo-morph nose dwindles in purity and frequency through southern Asia and northward through the hearts of the large islands of the Pacific among the inland tribes, except among the Tasmanians, Australians and Melanesians, to the inland tribes of the Philippine Islands, and eastward into Polynesia; through northern Asia into China and Japan, where in the latter place the nose is similar to that of the Mediterranean peoples; through northern Africa into the Soudan to the Guinea coast, and through eastern Africa to the Congo and along the south and east coasts up to the Guinea coast and the Congo again. The peoples who have this form of nose in greatest purity may be enumerated as follows: Danes and Scandinavians, North Germans, British, America whites in the United States and Canada, Spanish, Portuguese, some southern French and Italians, Greeks, Turks, Arabs, Jews and Gypsies. Those peoples among whom modified, yet fairly typical, forms are frequent are: East Indians, Iranians and Turanians, North and East Africans, Europeans other than those previously mentioned, Chinese, Japanese and Thibetans, Polynesians and Micronesians, and the inland tribes of the great islands of the Pacific, Java, Sumatra, Borneo, Celebes, and the Philippines.

The three forms of the nose may appear pure among any people, and in differentiating the three forms in any locality I use the terms hypo-onto-morph, meso-onto-morph and hyper-onto-morph because in every individual it may not be clear that the form of the nose is due to evolution-it may be developmental. The -onto-morph noses are not so strikingly different as the -phylomorph forms, but in any case the hypo-onto-morph resembles the hypo-phylo-morph, the meso-onto-morph resembles the mesophylo-morph, and the hyper-onto-morph resembles the hyperphylo-morph. 